\title{
VIBRATIONAL ANALYSIS OF [4-[(E)-PHENYLAZO] PHENYL]ETHANOL BASED ON THE COMPARISON BETWEEN THE EXPERIMENTAL AND DFT CALCULATED RAMAN SPECTRA
}

\author{
B. Minisini, ${ }^{1}$ G. Messager, ${ }^{1}$ I. Piyanzina, ${ }^{1,2}$ N. Delorme,${ }^{3}$ \\ and J.-F. Bardeau ${ }^{3}$
}

UDC 543.422:548.737

\begin{abstract}
In this work we assessed the performance of the density functional theory (DFT) approach through a comparison study with the experimental Raman spectrum obtained for [4-[(E)-phenylazo]phenyl]ethanol $(\mathrm{ABOH})$ in the wave number range $900-1800 \mathrm{~cm}^{-1}$. The assignment of the ten most active vibrational modes is achieved using the hybrid B3LYP method with the $6-311++\mathrm{G}(2 d, 2 p)$ basis set. Two molecules of reference [N-ethyl-4-[(E)-(4-nitrophenyl)azo]anilino]ethanol (Disperse Red 1, DR1) and 4-[(E)-(4-nitrophenyl)azo]aniline (Disperse Orange 3, DO3) are also investigated in order to consider this method in the calculation of the Raman intensities. The experimental Raman spectrum of DR1 is compared with those of the three stable configurations obtained at the B3LYP/6-311++G(2d,2p) level.
\end{abstract}

DOI: $10.1134 / \mathrm{S} 0022476614050072$

Keywords: azo dye, DFT calculation, Raman spectra.

\section{INTRODUCTION}

Because of their unique characteristics [1] (spread over air-water interface [2, 3], disperse into porous materials to form hybrid organic-inorganic composites [4-6], graft onto polymers chains [7-9] or onto inorganic materials and surfaces [10-13]) azobenzene and its derivatives have been of great interest over the past two decades. The azobenzene derivatives which exhibit photoisomerization from the thermodynamically more stable trans isomer to the cis isomer (and vice versa) by irradiation with UV or visible light were extensively studied for their photochemical properties in solution $[1,14]$ and therefore for their ability to produce photochemical devices [16-18]. Birefringence, resulting from the alignment of azobenzene groups, was also investigated [18] as well as the linear and non-linear optical properties of the derivatives [20-23]. There has been a considerable worldwide research dedicated to their great potential for optical applications, including optical storage and holographic surface relief gratings [24-27], and active optical integrated circuits [28-30]. In recent years there have been increasing efforts toward the development of diverse azobenzene-based smart multifunctional materials [31-34] and the development of stimuli-responsive surfaces [12, 35-38].

${ }^{1}$ Institut Supérieur des Matériaux et Mécaniques Avancés du Mans, UNAM, Le Mans, France; bminisini@ismans.fr

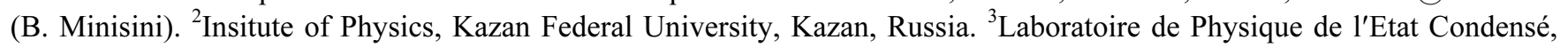
UMR CNRS 6087, Institut de Recherche en Ingénierie Moléculaire et Matériaux Fonctionnels FR2575, Université du Maine, France; Jean-Francois.Bardeau@univ-lemans.fr (J.-F. Bardeau). The text was submitted by the authors in English. Zhurnal Strukturnoi Khimii, Vol. 55, No. 5, pp. 889-897, September-October, 2014. Original article submitted February 7, 2013. 
The physical and chemical properties of the elaborated samples depend on both different molecular groups used as ring substituents and stability of the trans/cis configurations [39,40]. Consequently, under illumination, each type of azobenzene derivatives has its own steady state composition and the different configurations as well as the knowledge of the conversion mechanism are crucial for the identification and quantification. For these reasons, various spectroscopic techniques have been extensively used, including UV-Vis optical absorption experiments [41,43] and vibrational spectroscopy [39]. The $\mathrm{N}=\mathrm{N}$ stretching vibration, characteristic of the azobenzene group, can be involved in several vibrational bands, which makes the assignment of the Raman spectra more difficult. Consequently, from the middle of the 90 's, theoretical studies were performed to improve the assignment and description of the normal modes in azobenzene and their derivatives [43-51]. In this study, we assessed the capacity of the B3LYP/6-311++G(2d,2p) method to reproduce the Raman spectra of 2-[N-ethyl-4-[(E)-(4-nitrophenyl)azo]anilino]ethanol (Disperse Red 1, DR1) and 4-[(E)-(4-nitrophenyl)× azo]aniline (Disperse Orange 3, DO3) as reference compounds, and more specifically 2-[4-[(E)-phenylazo]phenyl]ethanol $(\mathrm{ABOH})$. The Raman spectra calculated for the molecules in the stable trans $(E)$ configuration were compared to experimental ones and discussed hereafter in the aim of assigning the most intense and characteristic ten vibrational bands in the wave number range $900-1800 \mathrm{~cm}^{-1}$.

\section{METHODS AND CALCULATIONS}

Experimental. The 2-[N-ethyl-4-[(E)-(4-nitrophenyl)azo]anilino]ethanol (Disperse Red 1:DR1) and 4-[(E)-(4nitrophenyl)azo]aniline (Disperse Orange 3:DO3) powders purchased from Aldrich were used without any further purification. 2-[4-[(E)-phenylazo]phenyl]ethanol (ABOH) was synthesized following the procedure described earlier [12]. Chloroform ( $\mathrm{CHCl}_{3}$, CAS Reg. No. 67-66-3 ) in its pure state (Merck, Pro Analysis Grade) was used as a solvent to dissolve the azo dyes. The sample concentrations were about $10^{-5} \mathrm{M}$.

Raman experiments were performed on a Jobin-Yvon-Horiba T64000 Raman spectrometer equipped with a single monochromator (600 gratings $\mathrm{mm}^{-1}$ ), coupled to a nitrogen cooled CCD detector and an Argon-Krypton laser (Coherent) emitting an incident light beam at $514.5 \mathrm{~nm}$ with a laser output power between $40 \mathrm{~mW}$ and $50 \mathrm{~mW}$. The Raman spectra were collected over a wave number range $900-1800 \mathrm{~cm}^{-1}$ with an exposure time of $180-300 \mathrm{~s}$ for 4 scans in a backscattering geometry under a confocale microscope (Olympus BX41) with a X 50/0.80 numerical aperture microscope objective. The calibration was made using the singular, intense Raman peak at $1332 \mathrm{~cm}^{-1}$ of a diamond sample.

Computational details. All the calculations were performed using the GAUSSIAN03 [51] program with the DFT method. The hybrid B3LYP functional $[52,53]$ was used to take into account the exchange correlation potentials. The energies of the structures were calculated with a SCF convergence on the density matrix of $10^{-8}$ au. All of the molecular structures were optimized using the Berny algorithm [53] with the criteria for convergence being a maximum force less than $45 \cdot 10^{-5}$ au and a rms force less than $3 \cdot 10^{-4}$ au Based on our previous work on 4-[(E)-phenylazo]phenol [47], we tested two basis sets: $6-31 \mathrm{G}++(d, p)$ and $6-311 \mathrm{G}++(2 d, 2 p)$. The Raman spectra obtained were calculated with the different parameters used by default on the optimized structures. Concerning the molecular models, we built four and six configurations respectively for $\mathrm{ABOH}$ and DR1 depending on the dihedral angles of ethyl and ethylol groups. For DO3 only one configuration was studied.

\section{RESULTS AND DISCUSSION}

Structure and conformation. The energy stability of different conformers of DR1 and ABOH were confirmed by the vibrational frequency analysis, after optimizing the atomic positions. The absence of negative wave numbers ensured that some local minima had been found at the B3LYP/6-31++G $(d, p)$ level. New energy minimization and frequency calculations at the $\mathrm{B} 3 \mathrm{LYP} / 6-311++\mathrm{G}(2 d, 2 p)$ level were then performed from the previously minimized structures. For DR1, three different conformers were found to be stable with the two levels of theory. The most stable structure is given in Fig. 1. 


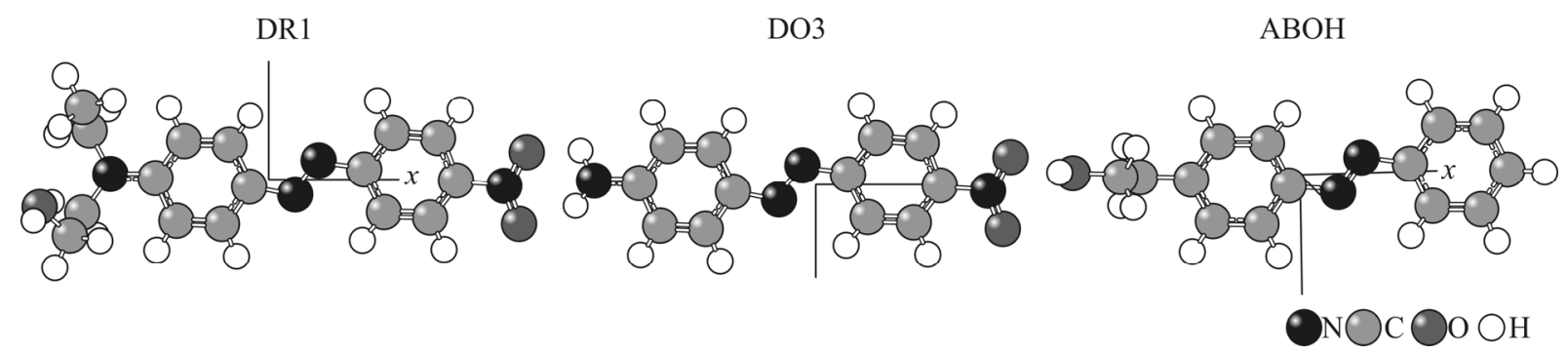

Fig. 1. Trans-configuration of [4'-[[hydroxy)ethyl]amino]-4-nitroazobenzene (Disperse Red 1, DR1), 4-amino-4nitroazobenzene (Disperse Orange 3, DO3), and 4-phenethylalcohol azobenzene (ABOH). Black atoms are nitrogen, dark grey atoms are carbon, light grey atoms are oxygen, and white atoms are hydrogen.

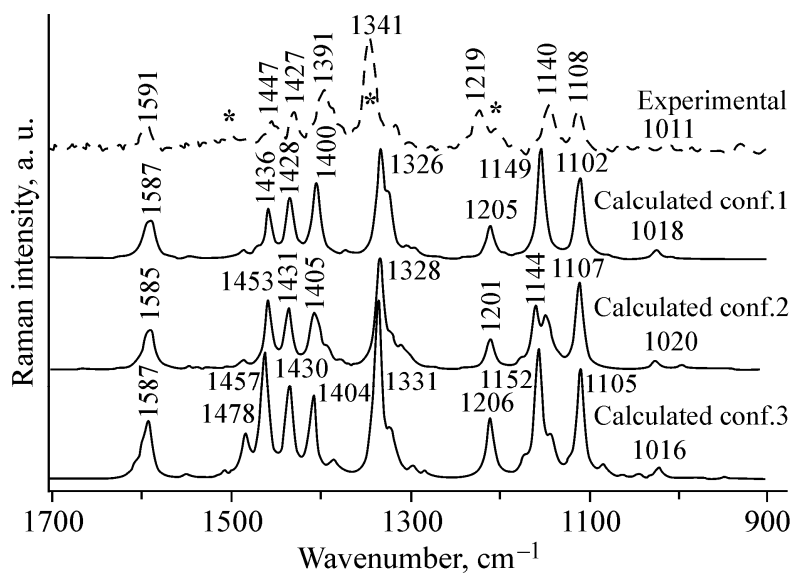

Fig. 2. Raman spectrum of DR1 in the solvent (chloroform) and B3LYP/6-311++G(2d,2p) calculated harmonic wave numbers with scaling factor representted with a Gaussian band with of $10 \mathrm{~cm}^{-1}$. The asterics represent the position of the experimental $\mathrm{CHCl}_{3}$ modes. Conf1 is for the most stable conformer.

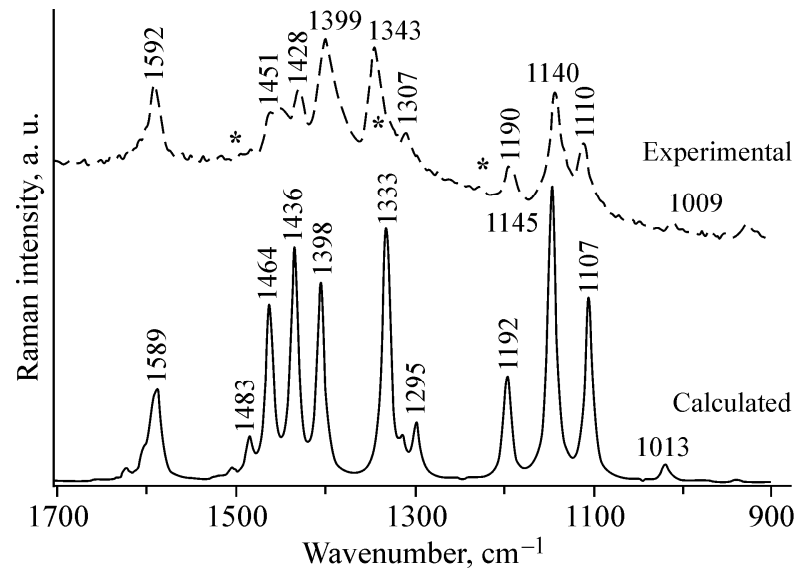

Fig. 3. Raman spectrum of $\mathrm{DO} 3$ in the solvent (chloroform) and B3LYP/6-311++G(2d,2p) calculated harmonic wave numbers with scaling factor representted with a Gaussian band with of $10 \mathrm{~cm}^{-1}$. The asterics represent the position of the experimental $\mathrm{CHCl}_{3}$ modes.

This conformer (Conf. 1) is $10 \mathrm{~kJ} / \mathrm{mol}$ more stable than the conformer with the ethyl group in the plane of the azobenzene rings and the ethylol group forming a dihedral angle of $78^{\circ}$ with respect to the ring (Conf. 2). Moreover, Conf. 1 is $112 \mathrm{~kJ} / \mathrm{mol}$ more stable than the conformer with the ethylol group in the plane and the ethyl group forming a dihedral angle of $75^{\circ}$ with respect to the ring (Conf. 3). Concerning $\mathrm{ABOH}$, two stable conformers were found at the $\mathrm{B} 3 \mathrm{LYP} / 6-31++\mathrm{G}(d, p)$ level while at the B3LYP/6-311++G(2d,2p) level only the structure visible in Fig. 1 has no imaginary wave numbers.

The numerical evaluation of the theoretical harmonic wave numbers $\left(v_{\text {theo }}\right)$ tends generally to overestimate the experimental ones. Consequently, the assignment of the vibrational modes is usually made after applying a scaling factor. In this study a linear law, $v_{\text {theo,scal }}=A v_{\text {theo }}+B$ was chosen. The parameters of the linear fit were determined using the most intense nine, ten, and eight bands respectively for DR1, DO3, and $\mathrm{ABOH}$ in the range 1000-1600 $\mathrm{cm}^{-1}$. After a linear fitting we found that $\mathrm{A}=0.9316,0.9395,0.9587$ and $\mathrm{B}=68.50 \mathrm{~cm}^{-1}, 55.36 \mathrm{~cm}^{-1}, 28.36 \mathrm{~cm}^{-1}$ given the correlation coefficients of 0.9972, 0.9982, and 0.9994 respectively for DR1, DO3, and ABOH. The experimental and scaled numerical Raman spectra of DR1, DO3, and $\mathrm{ABOH}$ are presented in Figs. 2, 3, and 4 respectively. The most intense ten bands of the Raman spectrum were assigned and discussed below in terms of four distinct wave number regions.

Vibrational spectral data. Region I (900-1100 $\left.\mathrm{cm}^{-1}\right)$. From the analysis of the experimental spectra, two distinct bands of weak intensities (barely visible for DR1) were observed. The first band located at $928 \mathrm{~cm}^{-1}$ for DR1 and DO3 was blue shifted to $934 \mathrm{~cm}^{-1}$ for ABOH. From the numerical results, the calculated intensities of the first peaks were only around $0.3 \%$ for the three compounds. Consequently, these bands were not visible on the numerical spectra. For azobenzenes, this 


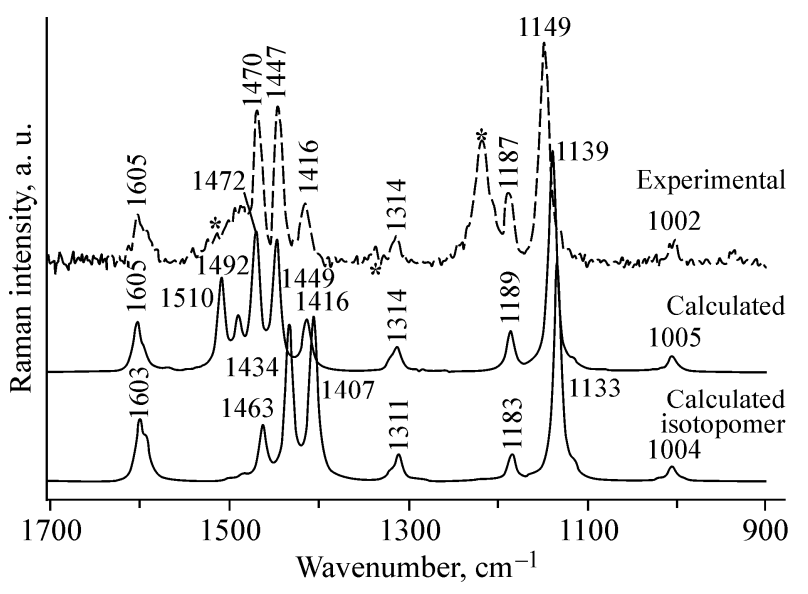

Fig. 4. Raman spectrum of $\mathrm{ABOH}$ in the solvent (chloroform) and B3LYP/6-311++G(2d,2p) calculated harmonic wave numbers with scaling factor representted with a Gaussian band with of $10 \mathrm{~cm}^{-1}$. The asterics represent the position of the experimental $\mathrm{CHCl}_{3}$ modes.

band observed experimentally at $938 \mathrm{~cm}^{-1}$ was previously assigned to the out-of-plane $\mathrm{C}-\mathrm{H}$ and torsion $\mathrm{C}-\mathrm{C}$ vibrations [44]. For 4,4'-azobis(pyridine N-oxide), the band observed at $927 \mathrm{~cm}^{-1}$ was also attributed to these vibrations [54]; whereas for para-substituted azobenzene derivatives, Lorriaux et al. [55] suggested that these bands be associated with the $\mathrm{C}-\mathrm{H}$ in-plane bending and the $\mathrm{Ph}-\mathrm{N}=\mathrm{N}-\mathrm{Ph}$ in-plane bending vibrations. According to our results, only one mode was revealed for $\mathrm{ABOH}$ and DO3 at $931 \mathrm{~cm}^{-1}$; whereas for DR1 two modes are present at $928 \mathrm{~cm}^{-1}$ and $933 \mathrm{~cm}^{-1}$. The mode at $928 \mathrm{~cm}^{-1}$ corresponded to the torsion of the methyl groups and the modes above at $930 \mathrm{~cm}^{-1}$ were associated with, as suggested by Lorriaux et al. [55], the $\mathrm{C}-\mathrm{H}$ in-plane bending and the $\mathrm{Ph}-\mathrm{N}=\mathrm{N}-\mathrm{Ph}$ in-plane bending vibrations. The intensities of the out-ofplane $\mathrm{C}-\mathrm{H}$ and the torsion $\mathrm{C}-\mathrm{C}$ vibrations calculated between $940 \mathrm{~cm}^{-1}$ and $990 \mathrm{~cm}^{-1}$ were too low to be visible in the spectra. Thus, the calculated spectra could not help us to interpret the blue shift observed for $\mathrm{ABOH}$.

The second band localized at $1011 \mathrm{~cm}^{-1}$ for DR1 and DO3 was red shifted to $1002 \mathrm{~cm}^{-1}$ for ABOH. Indeed, the most intense mode for $\mathrm{ABOH}$ was calculated at $1019 \mathrm{~cm}^{-1}$, with a scaled value at $1005 \mathrm{~cm}^{-1}$, and was associated with mode 12 described by Wilson [56] for the benzene molecule and defined as a trigonal planar ring bending by Rastogi et al. [57]. It corresponded to mode 18 of trans-azobenzene which was assigned to the in-plane bending $\mathrm{CC}$ and stretching CC modes by Biswas et al. [44]. Consequently, this mode for $\mathrm{ABOH}$ was due to the presence of an unsubstituted ring.

For the two other molecules, the two rings were para-substituted. According to our results, the mode calculated at $1024 \mathrm{~cm}^{-1}$, with scaled values of $1010 \mathrm{~cm}^{-1}$ and $1018 \mathrm{~cm}^{-1}$ respectively for DO3 and DR1, had the most important intensities in this region. Considering this, we decided to assign the experimental band at $1011 \mathrm{~cm}^{-1}$ to the $\mathrm{C}-\mathrm{H}$ in-plane bending and $\mathrm{C}-\mathrm{C}$ stretching vibrations of 4 nitrobenzene. As a result, the apparent red shift was not a real one since the origin of the activity of these modes is different: the presence of an unsubstituted ring for $\mathrm{ABOH}$ and of 4 nitrobenzene for DR1 and DO3.

Region II (1100-1250 $\left.\mathbf{~ c m}^{-1}\right)$. Three strong and well defined bands were observed in the experimental Raman spectra of $\mathrm{ABOH}$ and DO3; whereas four bands were present in this region for DR1. The bands located at $1108 \mathrm{~cm}^{-1}$ and $1110 \mathrm{~cm}^{-1}$ for DR1 and DO3 respectively were calculated at $1114 \mathrm{~cm}^{-1}$ and $1115 \mathrm{~cm}^{-1}$, with scaled values of $1111 \mathrm{~cm}^{-1}$ and $1106 \mathrm{~cm}^{-1}$. Since this mode was assigned to the $\mathrm{C}-\mathrm{NO}_{2}$ stretching mode, it was normal that no band was observed in the Raman spectrum of $\mathrm{ABOH}$.

The band observed around $1140 \mathrm{~cm}^{-1}$ is common to these three structures. However, being located at $1140 \mathrm{~cm}^{-1}$ for DR1 and DO3, this band was blue shifted to $1149 \mathrm{~cm}^{-1}$ for $\mathrm{ABOH}$. According to our results, this blue shift was not predicted since the modes were calculated at $1159 \mathrm{~cm}^{-1}, 1161 \mathrm{~cm}^{-1}$, and $1159 \mathrm{~cm}^{-1}$ for $\mathrm{ABOH}, \mathrm{DO} 3$, and DR1 respectively. The assignment that we suggested was thus in agreement with Biswas and Umapathy [44] for azobenzene, with a coupling 
between the phenyl-N stretching and $\mathrm{CH}$ in-plane bending mode 9a' [56]. We can also notice, as experimentally observed, that this band was the most intense for $\mathrm{ABOH}$. It was still the most intense out of the calculated modes for DR1, except for Conf. 2, and DO3 in disagreement with the experimental data. Different numerical and experimental factors can influence the Raman intensities. Indeed, Anariba et al. [58] have shown that despite complex pre-resonance enhancements, the intensity of this band was also strongly correlated to the laser polarization for nitroazobenzene grafted on pyrolyzed photoresist film, while Painelli et al. [59] have shown the effect of the solvent and the excitation lines on the relative intensities for [(S)-3pivaloyloxy-1-(4'-nitro-4-azobenzene)pyrrolidine]. From a numerical point of view, the Raman intensities, as a function of the third derivatives of the energies, are both dependant on the energetic models (basis set truncation, treatment of electron correlation), the methods and the parameters used to calculate the analytical and numerical derivatives [60]. Regarding azobenzene derivatives, different theoretical studies were performed with the aim of improving the assignment and the description of the normal modes [43-51]. Different methods were tested and although some important information was extracted, the questions concerning the chemistry models still remain open. Indeed, from the early work of Armstrong et al. [42] ab initio calculations performed at the MP2 6-31+G(d) level gave a satisfactory fit between the experimental and theoretical spectra for trans-azobenzene. Conversely, from a more recent study conducted by Kurita et al. [43], the authors concluded that the results obtained at the MP2 6-31G* level for trans-azobenzene and cis-azobenzene show a rather large error, concluding that the MP2 analysis was insufficient for predicting the vibrational frequencies. From the different results provided by density functional studies, it appears that not only the choice of the basis set is crucial, but also the choice of the functionals. Thus, testing different LDA, GGA and hybrid functionals, Biswas et al. [44] concluded that the best fit was obtained for BP86/6-31G* while Kurita et al. [43] reported that PW91PW91/6-31+G* was most accurate. The criteria used to sort these different methods were mainly based on the comparison between the experimental and numerical frequency modes. It is commonly accepted that the Raman intensities are best predicted by aug-cc-pVTZ or Sadlej's pVTZ [61, 62]. Yet, for our compounds the $6-311++\mathrm{G}(2 d, 2 p)$ basis set seemed to have work very well.

Finally, a medium intensity band was experimentally observed at $1189 \mathrm{~cm}^{-1}, 1193 \mathrm{~cm}^{-1}$, and $1200 \mathrm{~cm}^{-1}$ for ABOH, DR1, and DO3 respectively. Until the 80's, the assignment of this mode was speculative as confirmed by the discrepancies between the authors' statements summarized by Lorriaux et al. [55]. Based on normal coordinate calculations and the approximate atomic_displacements, we decided to assign the bands around $1190-1200 \mathrm{~cm}^{-1}$ to a coupling of the N-phenyl stretching and the $\mathrm{CH}$ in-plane bending mode $9 \mathrm{a}^{\prime}$. Still, even though the authors focused their analyses on the modes above $1400 \mathrm{~cm}^{-1}$, for trans-azobenzene this mode seemed to be not shifted when the measurements were performed with two ${ }^{15} \mathrm{~N}$ isotopes [62]. So, we evaluated the ABOH spectrum with two ${ }^{15} \mathrm{~N}$ isotopes, and we noticed a downshift by only $1 \mathrm{~cm}^{-1}$ for the mode initially at $1189 \mathrm{~cm}^{-1}$; whereas the mode at $1159 \mathrm{~cm}^{-1}$ was shifted by $6 \mathrm{~cm}^{-1}$. Hence, we can conclude that the coupling between the phenyl-N stretching and the $\mathrm{CH}$ in-plane bending mode $9 \mathrm{a}^{\prime}$ is weak for this mode in comparison to the mode around $1159 \mathrm{~cm}^{-1}$. Lorriaux et al. [55] have suggested linking the bond orders of the N-phenyl bonds of different azobenzene derivatives to the observed shift of this band. With this consideration, a high bond order would indicate a short bond length and a high wave number. From our results, the N-phenyl bond lengths were around $1.41 \AA$ for $\mathrm{ABOH}$ and were asymmetric for DO3 and DR1 with d(N-phenyl $\left.\left(\mathrm{NH}_{2}\right)\right)=1.41 \AA$ for both molecules whereas the other N-phenyl bond lengths were close to $1.39 \AA$. Consequently, the bond order of one of the N-phenyl bond was higher for DO3 and DR1 than for $\mathrm{ABOH}$, which might explain the observed shift even if it is not sufficient to explain the differences in the magnitude observed between DO3 and DR1.

It is also important to note that chloroform was used as a solvent for the three studied compounds and that the most intense Raman band for this solvent was located at $1216 \mathrm{~cm}^{-1}$. Consequently, this band might be superposed with the mode around $1200 \mathrm{~cm}^{-1}$ for other azobenzene derivatives.

Region III (1250-1360 cm$\left.~^{-1}\right)$. In this region, the strong intensity Raman band observed at $1341 \mathrm{~cm}^{-1}$ and $1343 \mathrm{~cm}^{-1}$ for DR1 and DO3 respectively was associated with the phenyl- $\mathrm{NO}_{2}$ stretching coupled with a ring vibration. Since this mode is related to the $\mathrm{NO}_{2}$ functional group vibration, no band is expected and found in the measured Raman spectrum of $\mathrm{ABOH}$. 


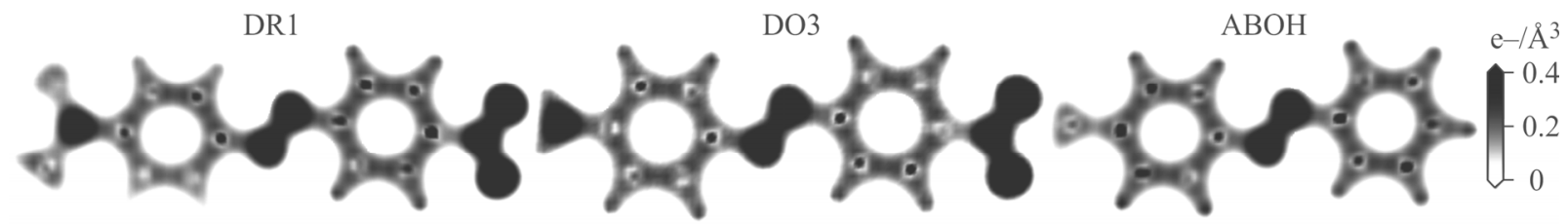

Fig. 5. Contour plots of the electron densities in the plane of three azobenzene derivatives : 2-[N-ethyl-4-[(E)-(4nitrophenyl)azo]anilino]ethanol (Disperse Red 1:DR1) and 4-[(E)-(4-nitrophenyl)azo]aniline (Disperse Orange 3:DO3) and 2-[4-[(E)-phenylazo]phenyl]ethanol (ABOH).

Moreover, a broad band with a weak intensity centered around $1310 \mathrm{~cm}^{-1}$ was observed in both Raman spectra and more clearly in the $\mathrm{ABOH}$ spectrum. According to our data, we assigned this band to the phenyl $\mathrm{CH}$ bending vibration. Subsequently for other compounds, only the numerical spectra can reveal the presence of this band. It should be pointed out that the weak-intensity Raman band observed at $1335 \mathrm{~cm}^{-1}$ (only visible in the $\mathrm{ABOH}$ experimental spectrum) was attributed to the solvent.

Region IV (1360-1700 $\left.\mathrm{cm}^{-1}\right)$. The main characteristic bands of the azo bond are observed in this spectral region. For azobenzene, the $\mathrm{N}=\mathrm{N}$ stretching mode was assigned over the ranges varying from $1420 \mathrm{~cm}^{-1}$ to $1556 \mathrm{~cm}^{-1}$ by different authors [64-68]. However, this mode contributes to a different band present in the region of $1360 \mathrm{~cm}^{-1}$ to $1700 \mathrm{~cm}^{-1}[49,62]$. For instance, according to our theoretical prediction, the mode calculated at $1391 \mathrm{~cm}^{-1}, 1397 \mathrm{~cm}^{-1}$, and $1416 \mathrm{~cm}^{-1}$ for DR1, $\mathrm{DO} 3$, and $\mathrm{ABOH}$ respectively, results actually from the $\mathrm{C}-\mathrm{C}$ antisymmetric stretching in the $\mathrm{NO}_{2}$ substituted phenyl for DO3 and DR1 and the ethylol-substituted ring for $\mathrm{ABOH}$ coupled with $\mathrm{CH}$ bending and $\mathrm{NN}$ stretching. Considering this, it is not so surprising that the two calculated vibrational modes were so close for DO3 and DR1. This mode decreased to $6 \mathrm{~cm}^{-1}$ when introducing two ${ }^{15} \mathrm{~N}$ while the Raman intensity increased drastically for $\mathrm{ABOH}$. The $\mathrm{C}-\mathrm{C}$ antisymmetric stretching vibrations of the second substituted phenyl were found at $1425 \mathrm{~cm}^{-1}$ and $1428 \mathrm{~cm}^{-1}$ respectively for DO3 and DR1. The blue shift observed for the second phenyl group can be explained by the difference in the bond order between the phenyl $\mathrm{NO}_{2}$ group and phenyl- $-\mathrm{N}\left(\mathrm{R}_{1} \mathrm{R}_{2}\right)$ with $\mathrm{R}_{1}=\mathrm{R}_{2}=\mathrm{H}$ for DO3 and $\mathrm{R}_{1}=\mathrm{C}_{2} \mathrm{H}_{5}, \mathrm{R}_{2}=\mathrm{C}_{2} \mathrm{H}_{4} \mathrm{OH}$ for DR1. Indeed, the phenyl- $\mathrm{NO}_{2}$ bond lengths were measured at $1.46 \AA$ for both DO3 and DR1 whereas the value for phenyl-N( $\left.\mathrm{R}_{1} \mathrm{R}_{2}\right)$ was $1.37 \AA$ for the two compounds. If we focus on the $\mathrm{N}=\mathrm{N}$ bond lengths we observed $1.251 \AA, 1.258 \AA$, and $1.261 \AA$ for $\mathrm{ABOH}, \mathrm{DO} 3$, and DR1 respectively. Nonetheless, the effect of the substitution was more visible for the phenyl $\mathrm{N}=$ bond lengths. Indeed, for $\mathrm{ABOH}$ the two bond lengths were close with values of $1.418 \AA$ and $1.416 \AA$; the last value is due to the substituted phenyl. However, for DO3 and DR1 the $\left(\mathrm{NO}_{2}\right)$ phenyl-N= bond lengths were $0.02 \AA$ longer than the other phenyl-N= distances. The slices of the electronic density for the three different compounds in the plane of the phenyl groups are presented Fig. 5.

It is worth noting that we obtained a plane configuration for both $\mathrm{ABOH}$ and $\mathrm{DO}$, but for DR1 the value of the $\mathrm{N}-\mathrm{N}-\mathrm{C}-\mathrm{C}$ angle, where the carbon atoms are for the phenyl $\mathrm{N}\left(\mathrm{R}_{1} \mathrm{R}_{2}\right)$ group, is more than $5^{\circ}$. The areas of high electronic density are shown in black and they are mainly centered on the $\mathrm{N}=\mathrm{N}, \mathrm{NO}_{2}$, and $\mathrm{N}-\left(\mathrm{R}_{1} \mathrm{R}_{2}\right)$ groups. If we focus on the phenyl $\mathrm{NO}_{2}$ and phenyl- $\mathrm{N}\left(\mathrm{R}_{1} \mathrm{R}_{2}\right)$ bonds, respectively on the right and the left of the figure, we can notice that the area of the phenyl$\mathrm{N}\left(\mathrm{R}_{1} \mathrm{R}_{2}\right)$ bond is darker and larger than for that of phenyl- $\mathrm{NO}_{2}$. Consequently, the electronic density is higher for the phenyl$\mathrm{N}\left(\mathrm{R}_{1} \mathrm{R}_{2}\right)$ bond than for the phenyl- $\mathrm{NO}_{2}$ bond, meaning a higher bond order, compatible with the idea of a lower bond length. Unfortunately, we cannot draw a similar conclusion concerning the azo bonds because the discrepancies in the qualitative results in Fig. 5 were not visible even for the higher density values.

The second band observed for $\mathrm{ABOH}$ at $1449 \mathrm{~cm}^{-1}$ was compatible with those of the third peak observed for DO3 $\left(1451 \mathrm{~cm}^{-1}\right)$ and DR1 $\left(1449 \mathrm{~cm}^{-1}\right)$. The vibrational modes were very complex since the $\mathrm{C}-\mathrm{C}$ stretching mode was coupled with the $\mathrm{C}-\mathrm{H}$ bending mode with carbon atoms belonging to the two phenyl groups, yet coupled with $\mathrm{N}-\mathrm{N}$ stretching. For $\mathrm{ABOH}$, this mode was most affected by the use of ${ }^{15} \mathrm{~N}$ since this mode was downshifted by $15 \mathrm{~cm}^{-1}$ in agreement with the experimental result of Meic et al. for azobenzene isotopomer [62]. Similar complex vibrations were observed in the band for $\mathrm{ABOH}$ at $1472 \mathrm{~cm}^{-1}$, but even though the vibrations are present in the two phenyl groups for $\mathrm{ABOH}$, only the $\mathrm{NO}_{2}-$ substituted phenyl group vibrates for DR1 and DO3. This could explain why the numerical Raman activity was weak, less 
than $10 \%$, for these two compounds comparing to $\mathrm{ABOH}(63 \%)$. The presence of isotopes leads to a decrease of $9 \mathrm{~cm}^{-1}$ of this mode for $\mathrm{ABOH}$, but the most important fact was a drastic drop in the intensity. In the numerical spectrum, two modes of medium activity at $1492 \mathrm{~cm}^{-1}$ and $1510 \mathrm{~cm}^{-1}$ could be observed. The most important discrepancy with the experimental spectrum is due to the activity of the second mode which was overestimated. This mode corresponds to $\mathrm{C}-\mathrm{H}$ bending in the substituted phenyl group, $\mathrm{N}=\mathrm{N}$ stretching, and $\mathrm{C}$-phenyl stretching vibrations, where the carbon atom belongs to the ethylol group. It is interesting to notice that modes 67 and 69 are inactive for the isotopomer.

Finally, we observed a broad band of a medium intensity at $1586 \mathrm{~cm}^{-1}$ for DO3 and DR1 and $1605 \mathrm{~cm}^{-1}$ for ABOH. These broad bands could be divided from numerical results into two modes for ABOH and three modes for both DR1 and DO3. All these modes involved $\mathrm{C}-\mathrm{C}$ stretching of carbon atoms belonging to phenyl groups. For $\mathrm{ABOH}$, the most intense bands were for the substituted phenyls, whereas for DR1 and DO3 the highest Raman intensities were found for the vibrations involving the $\mathrm{NO}_{2}$-substituted phenyl. The latter mode is weakly coupled with $\mathrm{N}=\mathrm{N}$ stretching since this mode for $\mathrm{ABOH}$ is downshifted by only $2 \mathrm{~cm}^{-1}$ for the isotopomer.

\section{CONCLUSIONS}

The aim of this study was to assign the fundamental bands observed in the experimental Raman spectra recorded for the wave number range $900-1800 \mathrm{~cm}^{-1}$ for $[4-[(E)$-phenylazo]phenyl]ethanol (ABOH). We used a hybrid DFT method on two reference DR1 and DO3 azo dyes molecules to demonstrate that the B3LYP/6-311++G(2d,2p) method was reliable for the prediction of Raman intensities. Three stable conformations were found for DRlat this level of theory. The nine main bands of the experimental spectrum were explained with the theoretical spectrum calculated for the most stable conformations. The spectra of the two other conformations differed mainly by the splitting of the mode located around $1140 \mathrm{~cm}^{-1}$. For DO3, the clarification of the experimental spectrum was more difficult in the range from $1400 \mathrm{~cm}^{-1}$ to

$1500 \mathrm{~cm}^{-1}$ due to the resonance effect. Nevertheless, the agreement between the two spectra is correct below $1300 \mathrm{~cm}^{-1}$.

Concerning the $\mathrm{ABOH}$ molecule, the most intense ten bands of the experimental spectrum were attributed based on the theoretical spectrum. Comparatively to DR1 and DO3, ABOH is a para mono substituted azo derivative. Seven modes out of the most intense ten bands of $\mathrm{ABOH}$ imply the in-plane vibrations of the two rings, whereas two modes involve the substituted ring and only one non-substituted. From the spectrum of $\mathrm{ABOH}$ calculated with two ${ }^{15} \mathrm{~N}$ it appears that four modes are shifted by more than $5 \mathrm{~cm}^{-1}$ and the activities of two other modes drastically decreased.

\section{REFERENCES}

1. J. Griffiths, Chem. Soc. Rev., 1, 481-493 (1972).

2. T. Martynski and J. Miyake, Z. Naturforsch., 58a, 97-102 (2003).

3. L. F. Ceridório, D. T. Balogh, L. Caseli, M. R. Cardoso, T. Viitala, C. R. Mendonça, and O. N. Oliveira Jr., J. Colloid. Interf. Sci., 346, 87-95 (2010).

4. M. Guendouz, N. Pedrono, R. Etesse, P. Joubert, J.-F. Bardeau, A. Bulou, and M. Kloul, Phys. Status Sol. A, 197, 414418 (2003).

5. M. Guendouz, M. Kloul, S. Haesaert, P. Joubert, J.-F. Bardeau, and A. Bulou, Phys. Status Sol. C, 2, 3453-3456 (2005).

6. J. Charrier, M. Kloul, P. Pirasteh, J. F. Bardeau, M. Guendouz, A. Bulou, and L. Haji, Opt. Mater., 30, 431-437 (2007).

7. P. Rochon, J. Gosselin, A. Natansohn, and S. Xie, Appl. Phys. Lett., 60, 4/5 (1992).

8. F. Poncin-Epaillard, J. Beunet, A. Bulou, and J.-F. Bardeau, J. Polym. Sci. Part A, 39, 3052-3061 (2001).

9. N. Delorme, J.-F. Bardeau, D. Debarnot, A. Bulou, and F. Poncin-Epaillard, Langmuir, 19, 5318-5322 (2000).

10. O. Prucker and J. Rühe, Macromol., 31, 592-601 (1998).

11. K. Tamada, J. Nagasawa, F. Nakanishi, K. Abe, T. Ishida, M. Hara, and W. Knoll, Langmuir., 14, 3264-3271 (1998).

12. N. Delorme, J.-F. Bardeau, A. Bulou, and F. Poncin-Epaillard, Langmuir, 21, 12278-12282 (2005). 
13. U. Jung, O. Filinova, S. Kuhn, D. Zargarani, C. Bornholdt, R. Herges, and O. Magnussen, Langmuir, 26, 13913-13923 (2010).

14. B. Marcandalli, A. Seves, E. Dubini-Paglia, and P. L. Beltrame, Dyes Pigments, 14, 79-88 (1990).

15. Z. F. Liu, K. Hashimoto, and A. Fujishima, Nature, 347, 658-660 (1990).

16. P. Makedonski, M. Brandes, W. Grahn, W. Kowalsky, J. Wichern, S. Wiese, and H. Johannes, Dyes Pigments, 61, 109119 (2004).

17. P. Rivolo, P. Pirasteh, A. Chaillou, P. Joubert, M. Kloul, J.-F. Bardeau, and F. Geobaldo, Sens. Act. B (Chemical), 100, 99-102 (2004).

18. T. Luckemeyer and H. Franke, Appl. Phys. Lett., 53, 2017-2019 (1998).

19. S. K. Yesodha, C. K. Sadashiva Pillai, and N. Tsutsumi, Prog. Polym. Sci., 29, $45-74$ (2004).

20. F. J. Rodriguez, C. Sanchez, B. Villacampa, R. Alcala, R. Cases, M. Millaruelo, and L. Oriol, Polymer, 45, 2341-2348 (2004).

21. P. Innocenzi and B. Lebeau, J. Mater. Chem., 15, 3821-3831 (2005).

22. R. Centore, S. Fusco, A. Peluso, A. Capobianco, M. Stolte, G. Archetti, and H.-G. Kuball, Eur. J. Org. Chem., 21, 3535-3543 (2009).

23. P. Rochon, E. Batalla, and A. Natansohn, Appl. Phys. Lett., 66, 136-139 (1995).

24. D. Brown, A. Natansohn, and P. Rochon, Macromol., 28, 6116-6123 (1995).

25. D. Y. Kim, S. K. Tripathy, L. Li, and J. Kumar, Appl. Phys. Lett., 66, 1166-1168 (1995).

26. O. N. Oliveira Jr., D. S. dos Santos Jr., D. T. Balogh, V. Zucolotto, and C. R. Mendonça, Adv. Colloid Interface Sci., 116, 179-192 (2005).

27. J. Paterson, A. Natansohn, P. Rochon, C. L. Callender, and L. Robitaille, Appl. Phys. Lett., 69, 3318-3321 (1996).

28. E. Sarailou, A. Gharavi, S. Javadpour, and V. Shkunov, Appl. Phys. Lett. 89, 171114-171117 (2006).

29. H. Karimi-Alavijeh, G. M. Parsanasab, M.-A. Baghban, E. Sarailou, A. Gharavi, S. Javadpour, and V. Shkunov, Appl. Phys. Lett., 92, 041105-041108 (2008).

30. Z. Sekkat and W. Knoll, Photoreactive Organic Thin Films, Academic Press, London, Amsterdam (2002).

31. M. Ogawa, T. Ishii, N. Miyamoto, and K. Kuroda, Appl. Clay Sci., 22, 179-185 (2003).

32. E. Delahaye, S. Eyele-Mezui, J.-F. Bardeau, C. Leuvrey, L. Mager, P. Rabu, and G. Rogez, J. Mater. Chem., 19, 61066115 (2009).

33. Y. Zhao and T. Ikeda, Smart Light-Responsive Materials: Azobenzene-Containing Polymers and Liquid Crystals, Wiley-Interscience, New-Jersey (2009).

34. K. Ichimura, S. K. Oh, and M. Nakagawa, Science, 288, 1624-1626 (2000).

35. F. Hamelmann, U. Heinzmann, U. Siemeling, F. Bretthauer, and J. Vor der Brüggen, Appl. Surf. Sci., 222, 1-5 (2004).

36. P. Uhlmann, L. Ionov, N. Houbenov, M. Nitschke, K. Grundke, M. Motornov, S. Minko, and M. Stamm, Prog. Org. Coat., 55, 168-174 (2006).

37. R. H. El Halabieh, O. Mermut, and C. J. Barrett, Pure Appl. Chem., 76, 1445-1465 (2004).

38. H. Rau, In Photochemistry and Photophysics, J. F. Rabek (ed.), CRC Press, Boca Ratan (1990), Vol. 9, Chap. 4.

39. H. Rau and E. Lueddecke, J. Am. Chem. Soc., 104, 1616-1620 (1982).

40. H. Durr and H. B. Laurent, Photochromism: Molecules and Systems in Studies in Organic Chemistry, Elsevier, Amsterdam (1990).

41. W. Freyer, D. Brete, R. Schmidt, C. Gahl, R. Carley, and M. Weinelt, J. Photochem. Photobiol. A, 204, 102-109 (2009).

42. D. R. Armstrong, J. Clarkson, and W. E. Smith, J. Phys. Chem., 99, 17825-17831 (1995).

43. N. Kurita, S. Tanaka, and S. Itoh, J. Phys. Chem. A, 104, 8114-8120 (2000).

44. N. Biswas and S. Umapathy, J. Phys. Chem. A, 101, 5555-5566 (1997).

45. V. Stepanic, G. Baranovic, and V. Smrecki, J. Mol. Struct., 569, 89-109 (2001).

46. P. C. Chen and Y. C. Chieh, J. Mol. Struct., 624, 191-200 (2003). 
47. B. Minisini, G. Fayet, F. Tsobnang, and J. F. Bardeau, J. Mol. Model., 13, 1227-1235 (2007).

48. D. R. C. Matazo, R. A. Ando, A. C. Borin, and P. S. Santos, J. Phys. Chem. A, 112, 4437-4443 (2008).

49. X. Li, W. Li, Z. Li, X. Zhou, Z. Li, J. Qin, and J. Hu, Spectrochim. Acta, Part A, 79, 1976-1984 (2011).

50. M. J. Frisch, G. W. Trucks, H. B. Schlegel, G. E. Scuseria, M. A. Robb, J. R. Cheeseman, J. A. Montgomery Jr., T. Vreven, K. N. Kudin, J. C. Burant, J. M. Millam, S. S. Iyengar, J. Tomasi, V. Barone, B. Mennucci, M. Cossi, G. Scalmani, N. Rega, G. A. Petersson, H. Nakatsuji, M. Hada, M. Ehara, K. Toyota, R. Fukuda, J. Hasegawa, M. Ishida, T. Nakajima, Y. Honda, O. Kitao, H. Nakai, M. Klene, X. Li, J. E. Knox, H. P. Hratchian, J. B. Cross, V. Bakken, C. Adamo, J. Jaramillo, R. Gomperts, R. E. Stratmann, O. Yazyev, A. J. Austin, R. Cammi, C. Pomelli, J. W. Ochterski, P. Y. Ayala, K. Morokuma, G. A. Voth, P. Salvador, J. J. Dannenberg, V. G. Zakrzewski, S. Dapprich, A. D. Daniels, M. C. Strain, O. Farkas, D. K. Malick, A. D. Rabuck, K. Raghavachari, J. B. Foresman, J. V. Ortiz, Q. Cui, A. G. Baboul, S. Clifford, J. Cioslowski, B. B. Stefanov, G. Liu, A. Liashenko, P. Piskorz, I. Komaromi, R. L. Martin, D. J. Fox, T. Keith, M. A. Al-Laham, C. Y. Peng, A. Nanayakkara, M. Challacombe, P. M. W. Gill, B. Johnson, W. Chen, M. W. Wong, C. Gonzalez, and J. A. Pople, Gaussian, Inc., Wallingford CT (2004).

51. A. D. Becke, J. Chem. Phys., 98, 5648-5653 (1993).

52. C. Lee, W. Yang, and R. G. Parr, Phys. Rev. B, 37, 785-789 (1988).

53. H. B. Schlegel, J. Comp. Chem., 3, 214 (1982).

54. M. Muniz-Miranda, B. Pergolese, G. Sbrana, and A. Bigotto, J. Mol. Struct., 744, 339-343 (2005).

55. J. L. Lorriaux, J. C. Merlin, A. Dupaix, and E. W. Thomas, J. Raman Spectr., 8, 81-87 (1979).

56. E. B. Wilson, Phys. Rev., 45, 706-714 (1934).

57. V. K. Rastogi, V. Jain, M. A. Palafox, D. N. Singh, and R. A. Yadav, Spectrochim. Acta A, 57, 209-216 (2001).

58. F. Anariba, U. Viswanathan, D. F. Bocian, and R. L. McCreery, Anal. Chem., 78, 3104-3112 (2006).

59. A. Painelli, F. Terenziani, L. Angiolini, T. Benelli, and L. Giorgini, Chem. Eur. J., 11, 6053-6063 (2005).

60. M. D. Halls and H. B. Schlegel, J. Chem. Phys., 111, 8819-8825 (1999).

61. E. E. Zvereva, A. R. Shagidullin, and S. A. Katsyuba, J. Phys. Chem. A, 115, 63-69 (2011).

62. Z. Meic, G. Baranovic, V. Smrecki, P. Novak, G. Keresztury, and S. Holly, J. Mol. Struct., 408, 399-403 (1997).

63. M. J. Tecklenburg, D. J. Kosnak, A. Bhatnagar, and D. K. Mohanty, J. Raman Spectr., 28,755-763 (1997).

64. A. Gruger, N. LeCalvé, P. Dizabo, and J. Fillaux, J. Chim. Phys., 69, 291-298 (1972).

65. H. Hacker, Spectrochim. Acta, 21, 1989-2004 (1965).

66. J. L. Houben, G. Masetti, E. Campani, and G. Gorini, J. Raman Spectr., 13, 15-20 (1982).

67. V. Smrecki, G. Baranovic, G. Keresztury, and Z. Meic, J. Mol. Struct., 408, 405-408 (1997). 